Western University

Scholarship@Western

$1-1-2016$

\title{
Pincer-plus-one ligands in self-assembly with palladium(ii): a molecular square and a molecular tetrahedron
}

Ava Behnia

The University of Western Ontario

Paul D. Boyle

The University of Western Ontario

Mahmood A. Fard

The University of Western Ontario

Johanna M. Blacquiere

The University of Western Ontario, jblacqu2@uwo.ca

Richard J. Puddephatt

The University of Western Ontario

Follow this and additional works at: https://ir.lib.uwo.ca/chempub

Part of the Chemistry Commons

\section{Citation of this paper:}

Behnia, Ava and Boyle, Paul D. and Fard, Mahmood A. and Blacquiere, Johanna M. and Puddephatt, Richard J.,"Pincer-plus-one ligands in self-assembly with palladium(ii): a molecular square and a molecular tetrahedron," Dalton Trans. 2016,4 5, 48, 19485-19490, The Royal Society of Chemistry http://dx.doi.org/10.1039/C6DT04264C 


\section{Journal Name}

\section{ARTICLE}

\section{Pincer-Plus-One Ligands in Self-Assembly with Palladium(II): A Molecular Square and a Molecular Tetrahedron}

Received 00th January 20xx, Accepted 00th January 20xx

DOI: $10.1039 / \times 0 \times x 00000 x$

www.rsc.org/

\author{
Ava Behnia, a Paul D. Boyle, ${ }^{a}$ Mahmood A. Fard, ${ }^{a}$ Johanna M. Blacquiere ${ }^{\text {a* }}$ and Richard J. \\ Puddephatt $^{\mathrm{a} *}$
}

The combination of a palladium(II) precursor with a diimine-phenol ligand and an oxidant $\left(\mathrm{H}_{2} \mathrm{O}_{2}\right.$ or $\left.\mathrm{O}_{2}\right)$ under different conditions has, serendipitously, given both a molecular square and a molecular tetrahedron by self-assembly of building blocks comprising palladium(II) centres coordinated to oxidised forms of the ligand.

\section{Introduction}

The application of chemical principles in combination with symmetry considerations has allowed the rational design of hundreds of nanoscale compounds of palladium(II) through self-assembly by dynamic coordination chemistry or by secondary bonding forces, such as hydrogen bonds or metallophilic attractions. ${ }^{1,2}$ Most two-component systems have used cis-blocked palladium(II) complexes as acceptors and bidentate or polydentate bridging ligands as donors. ${ }^{1,2}$ Palladium(II) complexes with tridentate ligands, usually terpyridine-based, have been used less often as acceptors in combination with bridging ligands as donors, and pincer ligands with appended hydrogen bonding groups for selfassembly have also given interesting oligomers and polymers. ${ }^{3,4}$ An intruiging ligand design for self-assembly involves both a mer-tridentate (i.e. pincer) component for coordination to one metal and a monodentate (i.e. pincerplus-one) donor for coordination to a second metal. However, a recent comprehensive review ${ }^{2}$ cited only one example of such a ligand with a terpyridine portion and an additional 3pyridyl substituent that self-assembles with palladium(II) to give a cyclic hexamer (Scheme 1), having a 12+ charge, as shown by TWIM-MS. ${ }^{5}$ This article reports two examples of unexpected ligand oxidation that converts a tridentate Schiffbase ligand to two different pincer-plus-one ligand structures. These archetectures promote the self-assembly of two different palladium(II) tetramers that are arranged in a molecular square or tetrahedron shape.

\footnotetext{
a Department of Chemistry, University of Western Ontario, London, Canada N6A 5B7. E-mail: johanna.blacquiere@uwo.ca; pudd@uwo.ca.

Electronic Supplementary Information (ESI) available: Details of the experimental and spectroscopic properties. X-ray data are available in CIF format (CCDC 1502360-1502362 ). See DOI: 10.1039/x0xx00000x
}

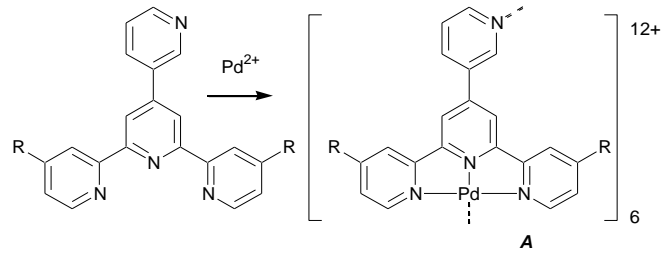

Scheme 1. Self-assembly of a pincer-plus-one ligand and $\mathrm{Pd}(\mathrm{II})$ to give a hexamer. ${ }^{5}$

\section{Results and discussion}

The new tetramers were obtained serendipitously while studying the reaction of the diimine-phenol ligand, $1,^{6}$ with the organopalladium complex, $2{ }^{7}$ in the presence of oxidants hydrogen peroxide or dioxygen (Scheme 2). The original intention being that the diimine group would displace the 1,5cyclooctadiene (cod) ligand from $\mathbf{2}$ and that the phenol substituent would facilitate subsequent biomimetic oxidation chemistry. Rather, two tetramers, $\mathbf{3}$ and $\mathbf{4}$, were obtained, with both reactions involving ligand oxidation and loss of the hydrocarbon moiety present in precursor 2.

In the first reaction, an acetone solution of complex $\mathbf{2}$ was treated with hydrogen peroxide, followed by addition of ligand $\mathbf{1}$, to give tetramer $\mathbf{3}$, as a red solid. Characterization of $\mathbf{3}$ (vide infra) indicates that the building block unit in $\mathbf{3}$ is a neutral palladium(II) fragment with a tetradentate dianionic $\mathrm{N}_{2} \mathrm{O}_{2}-$ donor ligand, formed by oxidative coupling of an acetone molecule with the imine group of the parent ligand 1 . The pincer component of $\mathbf{3}$ contains both a 6-membered acnac ring and a 5-membered amidophenoxide ring, with the pyridyl group bridging to the neighboring palladium atom. 


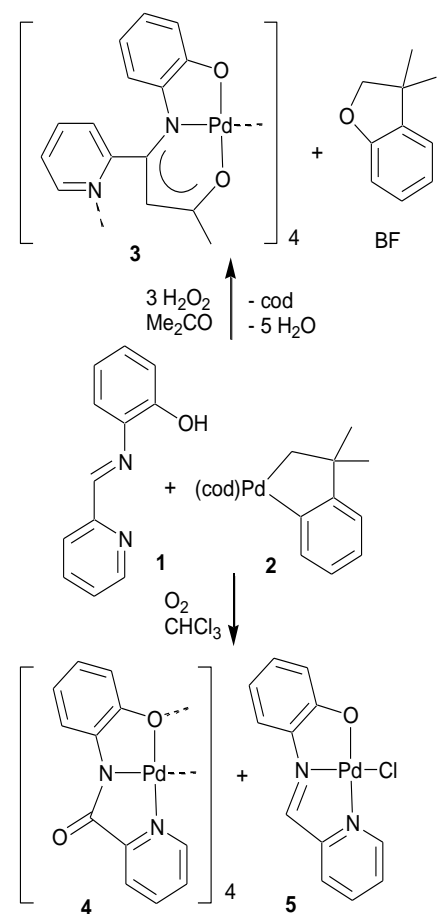

Scheme 2. Synthesis of complexes 3-5.

Small-scale ${ }^{1} \mathrm{H}$ NMR experiments were conducted in an attempt to optimize the reaction conditions and to reveal characteristics of the reaction pathway. Following the same conditions to those above, $\mathbf{3}$ is formed in 57\% yield and this is accompanied by benzofuran (BF) in a $30 \%$ yield. We have shown previously that oxidation of $\mathrm{Pd}$ (II) complexes related to 2 with excess $\mathrm{H}_{2} \mathrm{O}_{2}$ likewise affords $B F{ }^{7 b}$ The reaction involves oxidation-promoted oxygen-atom insertion into a Pd-aryl bond, followed by palladium oxidation and reductive elimination to release BF. While a similar process appears to be operative in the formation of $\mathbf{3}$, the mechanistic details are not yet determined. Critical to the reproducible formation of $\mathbf{3}$ is the described order of addition of reaction components. If metallation $(\mathbf{1}+2)$ precedes oxidation (addition of $\mathrm{H}_{2} \mathrm{O}_{2}$ ), numerous products are formed with no evidence for 3 . Alternatively, if $\mathrm{H}_{2} \mathrm{O}_{2}$ was added to ligand $\mathbf{1}$, followed by addition of 2, the tetramer $\mathbf{3}$ was not formed. As expected, a switch in solvent to $\mathrm{CHCl}_{3}$ does not afford 3, nor does a switch in oxidant to $\mathrm{O}_{2}$

The second tetramer $\mathbf{4}$ is obtained by reaction of a chloroform solution of $\mathbf{1}$ and $\mathbf{2}$ in the presence of dioxygen. Ligand $\mathbf{1}$ is again oxidized, but in this case an amido moiety is generated, with the incorporated oxygen atom likely orginating from the $\mathrm{O}_{2}$ oxidant. This is supported by the fact that tetramer $\mathbf{4}$ is not formed on conducting the reaction under $\mathrm{N}_{2}$. Characterization (vide infra) reveals that the pincer component of the ligand is comprised of the pyridyl, amido and phenoxide donors. The phenoxide bridges to a second metal to act also as the plusone portion of the ligand. This reaction is complex and gave a mixture of several palladium complexes and organic compounds, including BF. The green complex 4 was the principal product that was insoluble in acetone. The purple monometallic complex $\mathbf{5}$ was isolated from the acetonesoluble fraction, crystallized and analyzed by X-ray diffraction (Figure 1). The complex has been prepared previously, and the structure reported as a chloroform solvate. ${ }^{9}$ The bond parameters for the unsolvated form (Figure 1) are unexceptional, but they serve to illustrate the structure of the deprotonated ligand $\mathbf{1}$ in its expected simple pincer binding mode. ${ }^{9}$ Presumably the chloro ligand derives from the $\mathrm{CHCl}_{3}$ solvent used for the reaction.

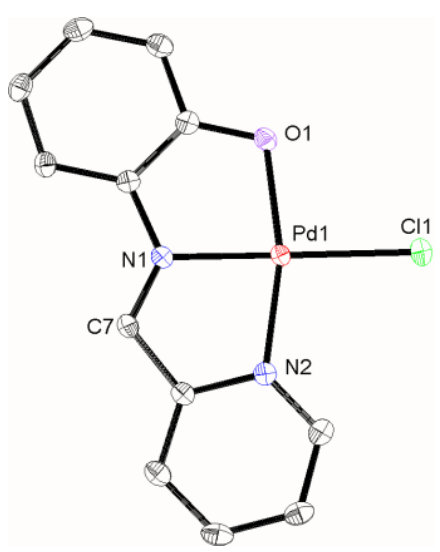

Figure 1. The structure of complex 5 (previously reported ${ }^{9}$ as a $\mathrm{CHCl}_{3}$ solvate). Selected bond parameters: $\operatorname{Pd}(1) \mathrm{N}(1)$ 1.951(2), $\operatorname{Pd}(1) \mathrm{N}(2)$ 2.017(3), $\operatorname{Pd}(1) \mathrm{O}(1) 2.011(2)$,

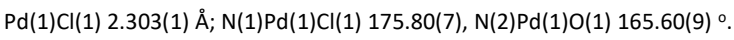

Both reactions to give $\mathbf{3}$ and $\mathbf{4}$ (Scheme 2) clearly involve multiple steps and intermediates, and the mechanisms are not yet understood. We note that the addition of deprotonated acetone to imine complexes ${ }^{6}$ and the oxidation of imines to amides mediated by $\mathrm{Pd}(\mathrm{II})^{8}$ are well established reactions. These transformations are needed for the formation of $\mathbf{3}$ and 4 , respectively.

Tetramers $\mathbf{3}$ and $\mathbf{4}$ were isolated and characterized by NMR and IR spectroscopy, MALDI mass spectrometry and elemental analysis. ${ }^{1} \mathrm{H}$ NMR spectra of $\mathbf{3}$ and $\mathbf{4}$ both reveal one set of ligand resonances that indicates the tetramers have four-fold symmetry in the solution state. The hydrocarbon ligand of the precursor $\mathbf{2}$ is not part of the structures and this is supported by the absence of signals in the aliphatic region that would be diagnostic for the methyl and methylene groups. For complex 3, ligand oxidation and acetone coupling is evident from the absence of the imine singlet of $\mathbf{1}$ and the appearance of singlets for the acnac $\mathrm{CH}$ and methyl moieties at 5.92 and 1.64 ppm, respectively. The downfield location of the former is typical for this site in other $\mathrm{M}$ (acnac) complexes. ${ }^{10}$ The imine resonance is likewise absent in the ${ }^{1} \mathrm{H}$ spectrum for 4 consistent with oxidation to an amide moiety. The tetrameric nature of both $\mathbf{3}$ and $\mathbf{4}$ was confirmed by charge-transfer MALDI MS analysis in which the molecular cation is observed at $\mathrm{m} / \mathrm{z} 1433.8$ and 1273.9 , respectively (Figure 2). Small deviations between the observed and simulated isotope patterns may be due to the contribution of an ionization pathway involving protonation to give an overlapping signal 
for $[\mathrm{M}+\mathrm{H}]^{+}$. The molecular square (3) fragments in the gas phase to give signals for both the loss of one ligand and one Pd-L unit at $m / z=1181.8$ and 1075.9 , respectively. In contrast, the molecular tetrahedron 4 fragments to give a dimer. The different fragmentation pathways may reflect the potential for metallophillic interactions in $\mathbf{4}$, but not 3 .

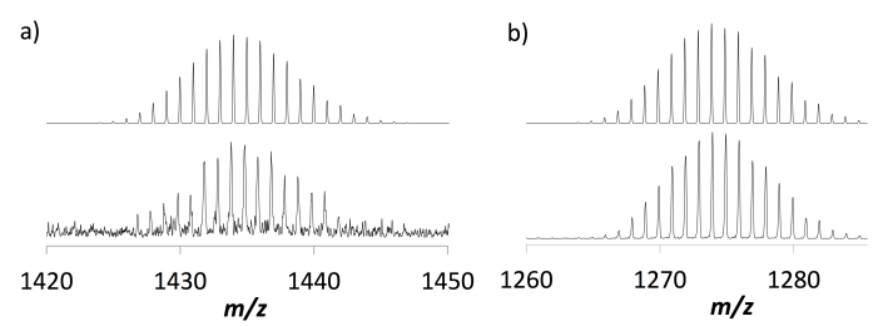

Figure 2. Simulated (top) and observed (bottom) MALDI MS isotope patterns for a) $[3]^{\bullet+}$, and b) $[4]^{\bullet+}$. Matrix $=$ pyrene.

Both complexes $\mathbf{3}$ and $\mathbf{4}$ are neutral and amenable to crystallization, in contrast to the highly charged complex $\boldsymbol{A}$, their only analog. Figure 3 shows a single building block, with pincer-plus-one ligation, and the shape of the molecular tetramer for each 3 and 4 . In both cases, loss of the hydrocarbon ligand and oxdiation of the imine fragment is evident from the structures. In each case, the palladium(II) centre has distorted square planar stereochemistry with trans, trans- $\mathrm{PdN}_{2} \mathrm{O}_{2}$ and cis, cis- $\mathrm{PdN}_{2} \mathrm{O}_{2}$ coordination in $\mathbf{3}$ and $\mathbf{4}$, respectively. Compound $\mathbf{3}$ shows the most significant distortion of the pincer moiety with an angle of $6.7^{\circ}$ found between a plane defined by the carbon atoms of the acnac ring and the Pd square plane.

The four palladium atoms in $\mathbf{3}$ have the shape of a distorted square, with edge distances 5.61 and $5.78 \AA$, longer diagonal distances of 7.62 and $7.72 \AA$, and internal angles of 84 and $85^{\circ}$. In contrast, the palladium atoms in $\mathbf{4}$ define a distorted tetrahedron, with all six Pd...Pd distances in the range $3.24-$ $3.58 \AA$ and with internal angles in the range $56-64^{\circ}$. The shorter Pd...Pd distances in $\mathbf{4}$ are consistent with the presence of weak metallophilic bonding, but there are clearly no metalmetal interactions in $\mathbf{3}$.

The full structures of $\mathbf{3}$ and $\mathbf{4}$ are shown in Figures 4 and 5, respectively. The Pd...Pd separations are controlled mostly by the nature of the bridging between $\mathrm{Pd}$ (pincer ligand) units and are naturally longer in $\mathbf{3}$ than in $\mathbf{4}$. This extra bridging can occur on either side of the roughly planar $\mathrm{Pd}$ (pincer ligand) unit and so each building block can have either $P$ or $M$ conformational chirality. ${ }^{11}$ The self-assembly to give tetramers, in which the stereochemistry is locked in, can then occur by: 1) selfrecognition to give racemic $P P P P / M M M M$ isomers, 2) selfdiscrimination to give the achiral $P M P M$ isomer, or 3) a more random way to include the racemic $P P P M / P M M M$ isomers. In both $\mathbf{3}$ and $\mathbf{4}$ the self-assembly occurs by self-discrimination. In the solid state, $\mathbf{3}$ and $\mathbf{4}$ have crystallographically imposed $C 2$ and $C 1$ symmetry respectively, but both have approximate $S 4$ symmetry and this is consistent with the highly symmetric ${ }^{1} \mathrm{H}$

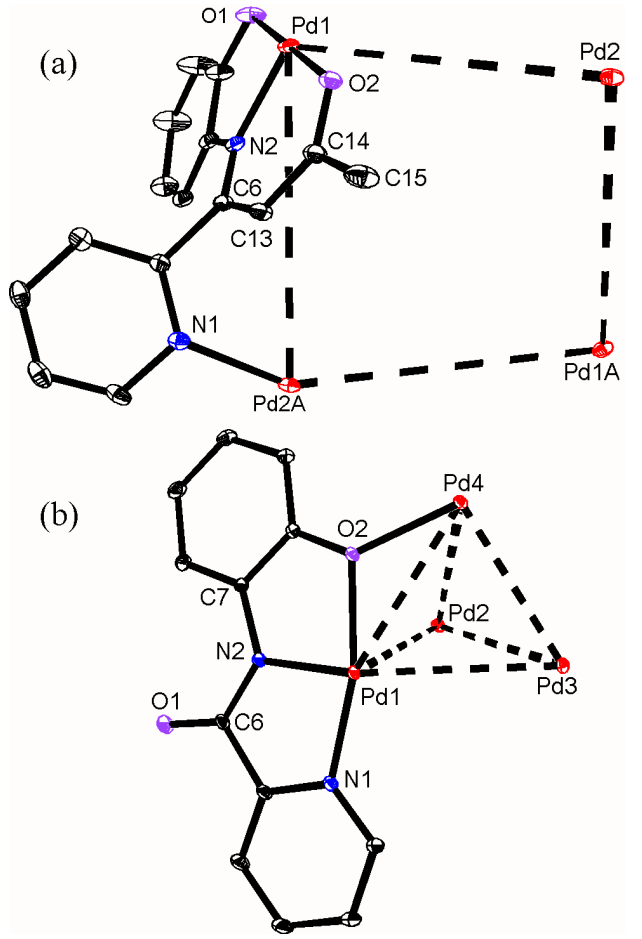

Figure 3. The building block and polyhedral structure in (a) $\mathbf{3}$ and (b) 4 .

NMR spectra discussed above. Most known molecular tetrahedra contain octahedrally coordinated metal ions and usually self-assemble by self-recognition. ${ }^{1,12}$ There are only a few examples of molecular tetrahedra with square planar metal centres and they all have much longer Pd...Pd separations than in 4.1,2,13 The shortest Pd...Pd separations in 4 may result from a combination of $\pi$-stacking and metallophilic bonding effects (Figure 5).

\section{Conclusions}

The structures of two interesting tetramers are described. Several degrees of serendipity are involved in their synthesis. The ligand $\mathbf{1}$ is oxidised in both cases, but in very different ways to form dianionic pincer ligands in the complexes $\mathbf{3}$ and 4. The neutral palladium(II)-pincer ligand fragments have an additional donor group and a vacant site at palladium(II) and they self-assemble to give tetramers in both cases. Both the molecular square in $\mathbf{3}$ and tetrahedron in $\mathbf{4}$ are new structural types, each having the unusual $\$ 4$ symmetry. ${ }^{1-3,11,12}$ None of this unprecedented chemistry was predicted in advance, but it is important to recognise that the pincer-plus-one ligand design has great potential for the designed synthesis of oligomeric and polymeric complexes with unusual structures, properties and potential uses. The syntheses of $\mathbf{3}$ and $\mathbf{4}$ presented here are reproducible under the defined experimental conditions, but given the long reaction times (and low yields in the case of 4 ) we suggest the formation of $\mathbf{3}$ and 4 serve to inspire intentional synthesis of the oxidized ligands ${ }^{14}$ for the purposes of self-assembly of nanoscale structures. 


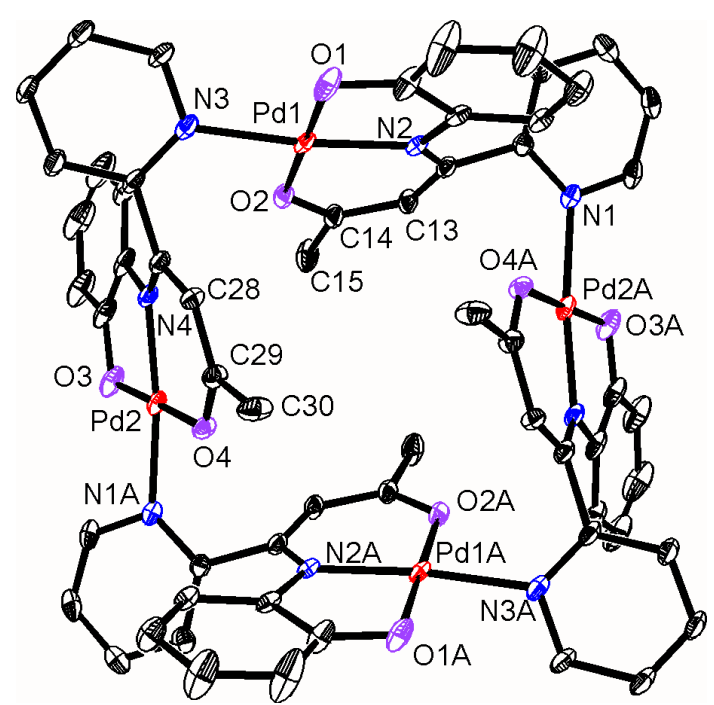

Figure 4. The structure of complex 3. Selected bond parameters: $\operatorname{Pd}(1) \mathrm{N}(2) 1.957(3)$ $\mathrm{Pd}(1) \mathrm{O}(1) 1.971(3), \mathrm{Pd}(1) \mathrm{O}(2) 1.977(3), \mathrm{Pd}(1) \mathrm{N}(3) 2.061(3) \AA ̊ \%$ O(1) Pd(1)O(2) 179.78(13), $\mathrm{N}(2) \operatorname{Pd}(1) \mathrm{N}(3) 173.59(14)^{\circ}$.

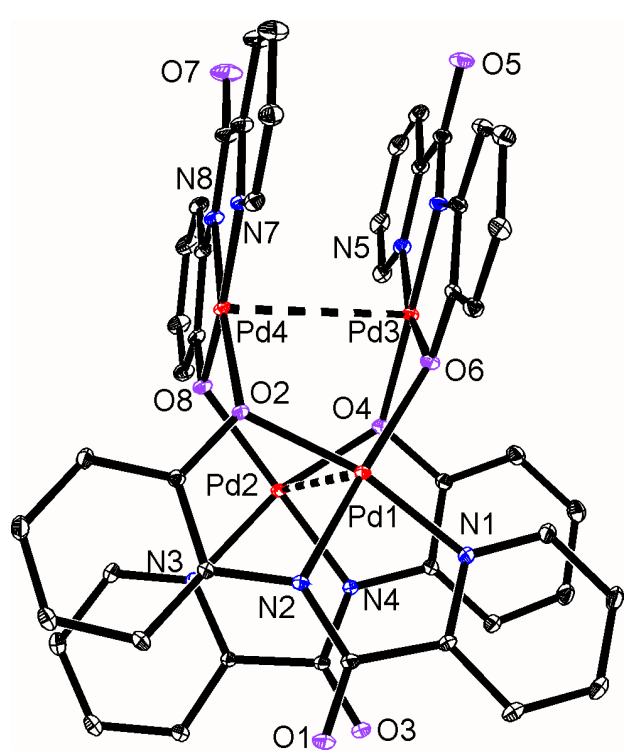

Figure 5. The structure of complex 4. Selected bond parameters: $\operatorname{Pd}(1) N(1) 1.977(1)$, $\mathrm{Pd}(1) \mathrm{N}(2)$ 1.931(1), $\mathrm{Pd}(1) \mathrm{O}(2)$ 2.033(1), $\mathrm{Pd}(1) \mathrm{O}(6)$ 2.042(1), $\mathrm{Pd}(1) \mathrm{Pd}(2) \quad 3.238(1) \AA$ $\mathrm{N}(1) \mathrm{Pd}(1) \mathrm{O}(2) 166.43(5), \mathrm{N}(2) \mathrm{Pd}(1) \mathrm{O}(6) 178.10(5)^{\circ}$.

\section{Experimental}

NMR spectra were recorded at $298 \mathrm{~K}$ using a Varian Inova 600 $\mathrm{MHz}$ spectrometer. ${ }^{1} \mathrm{H}$ and ${ }^{13} \mathrm{C}$ chemical shifts are reported relative to tetramethylsilane. Complete assignments of each compound were aided by the use of ${ }^{1} \mathrm{H}-{ }^{1} \mathrm{H}$ gCOSY, ${ }^{1} \mathrm{H}-{ }^{13} \mathrm{C}$ $\mathrm{HSQC}$, and ${ }^{1} \mathrm{H}-{ }^{13} \mathrm{C}$ HMBC experiments and are reported using the labeling scheme in Chart 1.

Commercial reagents and aqueous $30 \% \quad \mathrm{H}_{2} \mathrm{O}_{2}$ were used without further purification. The complex $\left[\mathrm{Pd}\left(\mathrm{CH}_{2} \mathrm{CMe}_{2} \mathrm{C}_{6} \mathrm{H}_{4}\right)(\mathrm{COD})\right]^{1}$ and the diimine ligand, 2-(pyridin-2ylmethyleneimino)phenol $^{2}$ were synthesized according to the literature procedures. Elemental analyses were performed by Laboratoire d'Analyze Élémentaire del'Université de Montréal. Organic products were analyzed using a Shimadzu GCMSQP2010 Ultra GC with a DB-5 column. MALDI-TOF mass spectra were collected using an AB Sciex 5800 TOF/TOF mass spectrometer using pyrene as the matrix in a 20:1 matrix:substrate molar ratio.

Chart 1. NMR labeling scheme for complexes made in this study.

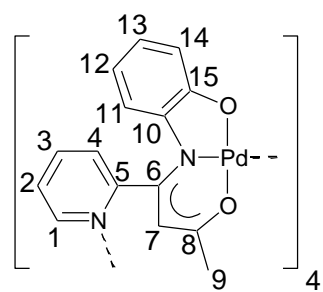

3
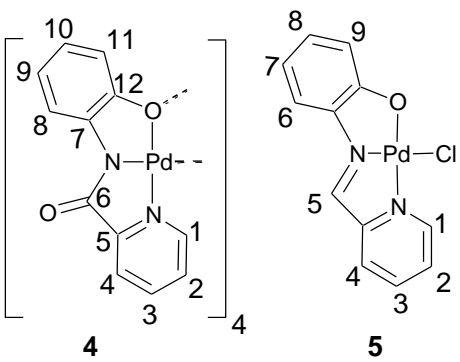

\section{Complex 3}

To a stirred solution of $\left[\mathrm{Pd}\left(\mathrm{CH}_{2} \mathrm{CMe}_{2} \mathrm{C}_{6} \mathrm{H}_{4}\right)(\mathrm{COD})\right]$ (0.090 g, 0.26 $\mathrm{mmol}$ ) in acetone $(5 \mathrm{~mL})$ was added a $30 \% \mathrm{H}_{2} \mathrm{O}_{2}$ solution $(79.5$ $\mu \mathrm{L}, 3$ equiv) via a micropipette syringe at room temperature. An immediate color change from yellow to sharp orange was observed. The mixture was allowed to stir for $2 \mathrm{~h}$. Then, the reaction flask was transferred to a $-65^{\circ} \mathrm{C}$ cold bath. Once the mixture cooled, a solution of $2-\mathrm{C}_{5} \mathrm{H}_{4} \mathrm{NCH}=\mathrm{N}-2-\mathrm{C}_{6} \mathrm{H}_{4} \mathrm{OH}(0.05 \mathrm{~g}$, $0.26 \mathrm{mmol}$ ) in acetone $(5 \mathrm{~mL})$ was added to the flask via syringe. The solution was stirred at low temperature and allowed to slowly reach room temperature over $6 \mathrm{~h}$. A color change from orange to dark red was observed over time. Next, the reaction flask was left for a night and bright red crystals were grown by slow evaporation of the solvent. Crystals were washed with hexane $(3 \times 2 \mathrm{~mL})$ and dried under high vacuum, to give 3 as an air-stable product $(0.03 \mathrm{~g}, 0.02 \mathrm{mmol}, 35 \%)$. NMR in $\mathrm{CDCl}_{3}: \delta\left({ }^{1} \mathrm{H}\right)=9.26(\mathrm{~d}, 1 \mathrm{H}, J=6 \mathrm{~Hz}, H 1), 7.82(\mathrm{t}, 1 \mathrm{H}, J=$ $8 \mathrm{~Hz}, H 3), 7.52$ (dd, $1 \mathrm{H}, J=8 \mathrm{~Hz}, 6 \mathrm{~Hz}, H 2), 7.32(\mathrm{~d}, 1 \mathrm{H}, J=8 \mathrm{~Hz}$, $H 4), 6.87(\mathrm{~d}, 1 \mathrm{H}, J=8 \mathrm{~Hz}, H 11), 6.78(\mathrm{t}, 1 \mathrm{H}, J=8 \mathrm{~Hz}, H 12), 6.09$ (t, $2 \mathrm{H}, J=8 \mathrm{~Hz}, H 13), 5.95$ (d, $1 \mathrm{H}, J=8 \mathrm{~Hz}, H 14), 5.92(\mathrm{~s}, 1 \mathrm{H}$, $H 7), 1.64(\mathrm{~s}, 3 \mathrm{H}, H 9) ; \delta\left({ }^{13} \mathrm{C}\right)=176.99(C 8), 165.91(C 10), 159.09$ (C6), 153.19 (C1 or $C 5), 153.11$ (C1 or $C 5), 141.35$ (C15), 139.25 (C3), 127.13 (C4), 125.97 (C12), 124.90 (C2), 121.92 (C11), 117.71 (C14), 112.70 (C13), 102.88 (C7), 23.85 (C9). MALDI MS (Pyrene matrix): Calc. $m / z 1434.7$ [3] ${ }^{\bullet+}$, Obs. $m / z$ 1434.7. Anal. Calc for $\mathrm{C}_{60} \mathrm{H}_{48} \mathrm{~N}_{8} \mathrm{O}_{8} \mathrm{Pd}_{4}$. $\left(\mathrm{CH}_{3}\right)_{2} \mathrm{CO}: \mathrm{C}, 50.53 ; \mathrm{H}, 3.54$. Found: $\mathrm{C}$, $50.67 ; H, 3.94$. Single crystals suitable for $X$-ray crystallographic analysis were grown by the slow evaporation of an acetone solution of the complex at room temperature. In a separate experiment, the similar reaction was carried out in acetone- $d_{6}$ containing dimethyl terephthalate as internal NMR standard. The yield of 3 in solution was determined to be $57 \%$, and the yield of the organic benzofuran product $B F$, identified by its ${ }^{1} \mathrm{H}$ NMR spectrum, ${ }^{1}$ was $30 \%$.

\section{Complexes 4 and 5}


A dilute solution of $2-\mathrm{C}_{5} \mathrm{H}_{4} \mathrm{NCH}=\mathrm{N}-2-\mathrm{C}_{6} \mathrm{H}_{4} \mathrm{OH}(0.17 \mathrm{~g}, 0.86$ mmol) in chloroform $(500 \mathrm{~mL})$ was added to a stirred dilute chloroform solution $(500 \mathrm{~mL})$ of $\left[\mathrm{Pd}\left(\mathrm{CH}_{2} \mathrm{CMe}_{2} \mathrm{C}_{6} \mathrm{H}_{4}\right)(\mathrm{COD})\right]$ $(0.30 \mathrm{~g}, 0.86 \mathrm{mmol})$ cooled to $-65^{\circ} \mathrm{C}$. The mixture was allowed to stir and slowly reach room temperature and stirring was continued for 4 weeks, during which time $\mathrm{O}_{2}$ gas was bubbled through the solution for 15 minutes every three days and the color of the solution changed from yellow to dark grey. Upon removal of the solvent under reduced pressure, a grey solid was formed. This solid was extracted with acetone $(3 \times 30 \mathrm{~mL})$. The insoluble fraction was identified as complex 4 , which was isolated as a green powder $(0.06 \mathrm{~g}, 0.05 \mathrm{mmol}, 22 \%)$. NMR in $\mathrm{CDCl}_{3}: \delta\left({ }^{1} \mathrm{H}\right)=7.80-7.74(\mathrm{~m}, 3 \mathrm{H}, H 3, H 4, H 8), 7.54(\mathrm{~d}, 1 \mathrm{H}, J=8$ $\mathrm{Hz}, H 11), 7.31$ (d, $1 \mathrm{H}, J=6 \mathrm{~Hz}, H 1), 6.79-6.75(\mathrm{~m}, 2 \mathrm{H}, H 2, H 9)$, $6.40(\mathrm{~m}, 1 \mathrm{H}, H 10) ; \delta\left({ }^{13} \mathrm{C}\right)=164.50(\mathrm{C} 6), 162.88(\mathrm{C} 12), 157.36$ (C5), $145.71(C 1), 139.30$ (C7), 139.17 (C3), 126.17 (C2), 125.89 (C8), 123.39 (C9), 120.76 (C11), 120.20 (C10), 119.16 (C4). MALDI MS (Anthracene matrix): Calc. $\mathrm{m} / z$ 1274.4 [4] ${ }^{\bullet+}$, Obs. $\mathrm{m} / z$ 1274.4. Anal. Calc. for $\mathrm{C}_{48} \mathrm{H}_{32} \mathrm{~N}_{8} \mathrm{O}_{8} \mathrm{Pd}_{4} .3 \mathrm{CHCl}_{3}: \mathrm{C}, 37.52 ; \mathrm{H}$ 2.16; N, 6.86. Found: C, 37.86; H, 2.98; N, 6.39\%. Single crystals suitable for X-ray crystallographic analysis were grown by slow diffusion of cyclohexane into a solution of 4 in $\mathrm{CHCl}_{3}$.

The acetone extracts were evaporated under vacuum to give complex 5 as a purple powder $(0.04 \mathrm{~g}, 0.13 \mathrm{mmol}, 15 \%)$. NMR in $\left(\mathrm{CD}_{3}\right)_{2} \mathrm{CO}: \delta\left({ }^{1} \mathrm{H}\right)=8.51(\mathrm{~d}, 1 \mathrm{H}, J=5 \mathrm{~Hz}, H 1), 8.31(\mathrm{~s}, 1 \mathrm{H}, \mathrm{H} 5)$, $8.17(\mathrm{t}, 1 \mathrm{H}, J=8 \mathrm{~Hz}, H 3), 7.84$ (d, $1 \mathrm{H}, J=8 \mathrm{~Hz}, H 4), 7.62$ (dd, $1 \mathrm{H}$, $J=8 \mathrm{~Hz}, 6 \mathrm{~Hz}, H 2), 7.33(\mathrm{~d}, 1 \mathrm{H}, J=8 \mathrm{~Hz}, H 6), 7.03(\mathrm{t}, 1 \mathrm{H}, J=8$ $\mathrm{Hz}, H 8), 6.48(\mathrm{~d}, 1 \mathrm{H}, J=8 \mathrm{~Hz}, H 9), 6.41(\mathrm{t}, 1 \mathrm{H}, J=8 \mathrm{~Hz}, H 7)$ in agreement with literature values. ${ }^{9}$ Single crystals suitable for $\mathrm{X}$-ray crystallographic analysis were grown by dissolving the product in chloroform, followed by slow evaporation of the solvent.

\section{X-ray structure determinations ${ }^{15}$}

In a typical experiment, the selected crystal was mounted on a Mitegen polyimide micromount with a small amount of Paratone $\mathrm{N}$ oil. All $\mathrm{X}$-ray measurements were made using a Bruker Kappa Axis Apex2 diffractometer at a temperature of $110 \mathrm{~K}$. The frame integration was performed using SAINT, and the resulting raw data were scaled and absorption corrected using a multi-scan averaging of symmetry equivalent data using SADABS. The structure was solved by using a dual space methodology using the SHELXT program. All non-hydrogen atoms were obtained from the initial solution. The hydrogen atoms were introduced at idealized positions and were allowed to ride on the parent atom. The structural model was fit to the data using full matrix least-squares based on $F^{2}$. The calculated structure factors included corrections for anomalous dispersion from the usual tabulation. The structure was refined using the SHELXL-2014 program from the SHELX suite of crystallographic software. Details are given in Table 1 and in the cif files. In complex 4, the lattice contained two $\mathrm{CHCl}_{3}$ molecules of solvation. One of the $\mathrm{CHCl}_{3}$ molecules was highly disordered and could not be fit to a chemically sensible model. The electron density associated with this moiety was masked out of the refinement using the SQUEEZE algorithm as implemented in PLATON. The other $\mathrm{CHCl}_{3}$ had a $\mathrm{Cl}$ atom disordered over two sites. The occupancy of the predominant orientation refined to a normalized value of $0.532(9)$.

Table 1. Crystal and Refinement Data.

\begin{tabular}{|c|c|c|c|}
\hline Complex & 3 & 4 & 5 \\
\hline formula & $\mathrm{C}_{63} \mathrm{H}_{54} \mathrm{~N}_{8} \mathrm{O}_{9} \mathrm{Pd}_{4}$ & $\mathrm{C}_{49} \mathrm{H}_{33} \mathrm{Cl}_{3} \mathrm{~N}_{8} \mathrm{O}_{8} \mathrm{Pd}_{4}$ & $\mathrm{C}_{13} \mathrm{H}_{10} \mathrm{Cl}_{4} \mathrm{~N}_{2} \mathrm{OPd}$ \\
\hline f.w. (g/mol) & 1492.74 & 1393.78 & 458.43 \\
\hline cryst. syst. & monoclinic & triclinic & monoclinic \\
\hline space gp. & $P 2 / n$ & $P-1$ & $\mathrm{P} 22_{1} / \mathrm{n}$ \\
\hline $\mathrm{T} / \mathrm{K}$ & 110 & 110 & 110 \\
\hline$a, \AA$ & $13.327(4)$ & $12.412(4)$ & $12.823(3)$ \\
\hline$b, \AA$ & $8.686(3)$ & $13.358(3)$ & $7.1043(14)$ \\
\hline$c, \AA$ & $25.305(7)$ & $17.436(4)$ & $16.997(6)$ \\
\hline$\alpha,{ }^{\circ}$ & 90 & $111.520(7)$ & 90 \\
\hline$\beta$, & $102.658(11)$ & $106.400(11)$ & $90.137(16)$ \\
\hline$v_{i}^{\circ}$ & 90 & $91.530(15)$ & 90 \\
\hline $\mathrm{V}, \AA^{3}$ & $2857.9(16)$ & $2552.3(11)$ & $1548.4(7)$ \\
\hline Z & 2 & 2 & 4 \\
\hline $\mathrm{d}$ (calc.) & 1.735 & 1.814 & 1.966 \\
\hline \multicolumn{4}{|l|}{$\left(\mathrm{Mg} / \mathrm{m}^{3}\right)$} \\
\hline$\lambda(\mathrm{MoK} \alpha), \AA$ & 0.71073 & 0.71073 & 0.71073 \\
\hline$\mu,\left(\mathrm{cm}^{-1}\right)$ & 1.305 & 1.604 & 1.886 \\
\hline $\operatorname{Max} 2 \theta^{\circ}$ & 66.392 & 86.626 & 48.982 \\
\hline reflns. & 88521 & 179839 & 32693 \\
\hline reflns $[I>2 \sigma(I)]$ & 10882 & 37874 & 2574 \\
\hline param. & 406 & 723 & 217 \\
\hline $\mathrm{R}_{1}[\mathrm{I}>2 \sigma(\mathrm{I})]$ & 0.0509 & 0.0393 & 0.0228 \\
\hline wR2 (all data) & 0.1228 & 0.1018 & 0.0748 \\
\hline
\end{tabular}

\section{Acknowledgements}

We thank the NSERC (Canada) for financial support.

\section{Notes and references}

1 Selected reviews: (a) T. R. Cook and P. J. Stang, Chem. Rev., 2015, 115, 7001; (b) S. Mukherjee and P. S. Mukherjee, Chem. Commun., 2014, 50, 2239; (c) M.D. Ward and P. R. Raithby, Chem. Soc. Rev., 2013, 42, 1619; (d) T. R. Cook, Y. R. Zheng and P. J. Stang, Chem. Rev., 2013, 113, 734; (e) R. Chakrabarty, P. S. Mukherjee and P. J. Stang, Chem. Rev., 2011, 111, 6810.

2 N. B. Debata, D. Tripathy and D. K. Chand, Coord. Chem. Rev., 2012, 256, 1831.

3 (a) S. Perera, X. Li, M. Soler, A. Schultz, C. Wesdemiotis, C. N. Moorefield and G. R. Newkome, Angew. Chem. Int. Ed., 2010, 49, 6539; (b) E.C. Constable, C. E. Housecroft and C. B. Smith, Inorg. Chem. Comm., 2003, 6, 1011; (c) R. D. Sommer, A. L. Rheingold, A. J. Goshe and B. Bosnich, J. Am. Chem. Soc., 2001, 123, 3940.

4 (a) N. C. Mehendale, M. Lutz, A. L. Spek, R. J. M. Klein Gebbink and G. van Koten, J. Organomet. Chem., 2008, 693, 2971; (b) O. Adeyi, W. B. Cross, G. Forrest, L. Godfrey, E. G. Hope, A. McLeod, A. Singh, K. Singh, G. A. Solan, Y. Wang and L. A. Wright, Dalton Trans., 2013, 42, 7710.

5 S. Perea, X. Li, M. Guo, C. Wesdemiotis, C. N. Moorefield and G. R. Newkome, Chem. Commun., 2011, 47, 4658. 
6 M. E. Moustafa, P. D. Boyle and R. J. Puddephatt, Chem. Commun., 2015, 51, 10334.

7 (a) F. Qu, J. R. Khusnutdinova, N. P. Rath and L. M. Mirica, Chem. Commun., 2014, 50, 3036; (b) A. Behnia, P.D. Boyle, J.M. Blacquiere and R.J. Puddephatt, Organometallics, 2016, 35, 2645.

8 Y. Suto, N. Yamagiwa and Y. Torisawa, Tetrahedron Lett., 2008, 49, 5732.

9 (a) I. Angurell, I. Martinez-Ruiz, O. Rossell, M. Seco, P. Gomez-Sal, A. Martin, M. Font-Bardia and X. Solans, J. Organomet. Chem., 2007, 692, 3882; (b) N. Gomez-Blanco, J.J. Fernandez, A. Fernandez, D. Vazquez-Garcia, M. LopezTorres and J.M. Vila, Eur. J. Inorg. Chem., 2009, 3071.

10 J.D. Crowley, A.J. Goshe, I.M. Steele and B. Bosnich, Chem.Eur.J. 2004, 1944.

11 G. Bringmann, A.J. Price Mortimer, P.A. Keller, M.J. Dresser, J. Garner and M. Breuning Angew. Chem. Int. Ed., 2005, 44, 5584.

12 (a) D. L. Caulder, R. E. Powers, T. N. Parac and K. N. Raymond, Angew. Chem. Int. Ed., 1998, 37, 1840; (b) J. S. Fleming, K. L. V. Mann, C.-A. Carraz, E. Psillakis, J. C. Jefferey, J. A. McCleverty and M. D. Ward, Angew. Chem. Int. Ed., 1998, 37, 1279; (c) W. Meng, T. K. Ronson and J. R. Nitschke, Proc. Nat. Acad. Sci., 2013, 110, 10531. (d) C. Giri, F. Topic, P. Mal and K. Rissanen, Dalton Trans., 2014, 43, 17889.

13 (a) S. M. Jansze, G. Cecot, M. D. Wise, K. O. Zhurov, T. K. Ronson, A. M. Castilla, A. Finelli, P. Pattison, E. Solari, R. Scopelliti, G. E. Zelinskii, A. V. Vologzhanina, Y. Z. Voloshin, J. R. Nitschke and K. Severin, J. Am. Chem. Soc., 2016, 138 2046; (b) C. Klein, C. Gutz, M. Bogner, F. Topic, K. Rissanen and A. Lutzen, Angew. Chem. Int. Ed., 2014, 53, 3739; (c) D. K. Chand, K. Biradha, M. Kawano, S. Sakamoto, K. Yamaguchi and M. Fujita, Chem. Asian J., 2006, 1, 82.

14 The free ligand in $\mathbf{3}$ appears to be unknown but the ligand in 4 is known, though the binding mode in $\mathbf{4}$ is not. D. S. Marlin, M. M. Olmstead and P. K. Mascharak, Eur. J. Inorg. Chem. 2002, 859.

15 (a) APEX 2, Crystallography software package; Bruker AXS Madison, WI, 2005. (b) SAINT, Data Reduction Software Bruker AXS: Madison, WI, 1999. (c) G.M. Sheldrick, SADABS v.2.01, Bruker AXS: Madison, WI, 2006. (d) G.M. Sheldrick Acta Cryst. A, 2008, 64A, 112. (e) A. L. Spek, Acta Cryst., 2015, C71, 9 